\title{
Late- versus early-onset geriatric depression in a memory research center
}

This article was published in the following Dove Press journal:

Neuropsychiatric Disease and Treatment

8 October 2009

Number of times this article has been viewed

\section{Carol Dillon' \\ Ricardo F Allegri \\ Cecilia M Serrano' \\ Mónica Iturry' \\ Pablo Salgado' \\ Frank B Glaser' \\ Fernando E Taragano² \\ 'Memory Research Center, Department of Neurology, Hospital \\ General Abel Zubizarreta, GCBA \\ Buenos Aires, Argentina; ${ }^{2}$ Department of Neuropsychology (SIREN), CEMIC \\ University, Buenos Aires, Argentina}

Correspondence: Carol Dillon Department of Neuropsychology (SIREN), CEMIC University. Galvan 4I02, (CI43IFWO) Buenos Aires, Argentina

Fax +54 || 45468227

Email drcaroldillon@yahoo.com.ar http// www.cemic.edu.ar/
Objective: To contrast early-onset ( $<60$ years) and late-onset ( $>60$ years) depression in geriatric patients by evaluating differences in cognition, vascular comorbidity and sociological risk factors. Both patient groups were compared with normal subjects.

Materials and methods: We recruited 76 patients with depressive symptoms (37 late onset and 39 early onset) and 17 normal controls matched by age and educational level. All subjects were assessed using a semistructured neuropsychiatric interview and an extensive neuropsychological battery. Vascular and sociological risk factors were also evaluated.

Results: We found a significant variation in performance between depressive patients and normal controls in most cognitive functions, especially memory $(P<0.0001)$, semantic fluency $(P<0.0001)$, verbal fluency, and digit-symbol $(P<0.0001)$. Late-onset depression patients scored lower and exhibited more severe impairment in memory domains than early-onset depression patients $(P<0.05)$. Cholesterol levels and marital status were significantly $(P<0.05)$ different between the depressive groups. Both depressed groups (early- and lateonset) were more inactive than controls ( $P<0.05$; odds ratio: 6.02$)$.

Conclusion: Geriatric depression may be a manifestation of brain degeneration, and the initial symptom of a dementia. It is important to consider this in the treatment of patients that exhibit late-onset depressive symptoms.

Keywords: early- and late-onset depression, geriatrics, cognition

\section{Introduction}

Aging is associated with brain lesions or other abnormalities that may contribute to depression. ${ }^{1-3}$ Among late-life depressive syndromes, late-onset depression has been conceptualized as a neurologic disease. This view has been supported by studies suggesting that late-onset depression is more often associated with cognitive impairment and neurologic comorbidity than early-onset depression. ${ }^{4-7}$

Comorbid neurologic disorders are not always clinically evident at the initial presentation of late-onset depression. Once developed, late-onset depression may have a slow or poor response to antidepressant treatment. ${ }^{8,9}$ Frontostriatal dysfunction may be one of the critical brain abnormalities contributing to late-life depression. Functional neuroimaging studies support this view as they have demonstrated abnormal metabolism in frontal regions and the caudate nucleus during depressive states. ${ }^{10,11}$ The consistency of findings implicating a dysfunction of frontostriatal pathways in geriatric depression has led to the depression-executive dysfunction (DED) syndrome hypothesis. This hypothesis postulates that in a subgroup of elderly patients with depression, frontostriatal dysfunction caused by cerebrovascular disease 
or other aging-related conditions is the main predisposing factor for depression. ${ }^{9}$ It has been further hypothesized that DED syndrome has a distinct clinical presentation and poor long-term and short-term outcomes. ${ }^{9}$

Major depressive disorder is a highly prevalent disease in old age. ${ }^{1-3}$ Between $1 \%$ and $4 \%$ of the elderly experience major depression and this prevalence increases to between $6 \%$ and $32 \%$ among older nursing home residents. ${ }^{4}$ Though the elderly constitute a major subgroup, depression frequently affects the younger population as well. In this demographic, initial onset typically occurs in the late twenties, but the first episodes are not usually seen until after the age of 40 years. $^{6,7}$

Epidemiologically, about $40 \%$ of cases of major depression in old age are characterized by recurrent depressive episodes, whereas only $30 \%$ reflect late-onset depression. In some cases, recurrent and late-onset depression is difficult to distinguish clinically. ${ }^{5}$

Late-onset depression is a heterogeneous syndrome that includes patients with high medical burden and neurologic disorders that may or may not be clinically evident upon initial onset. ${ }^{9}$

Several studies on late-onset depression focus on major depression but not on other subtypes, such as dysthymia, minor depression, unspecified mood disorder, mood disorder related to medical conditions (Alzheimer disease or other dementias), subsyndromal depression, etc. In a recent study by Rapp and colleagues comparing late onset with recurrent depression, patients in both groups were diagnosed with major depression. ${ }^{12}$

We hypothesize that late-onset depression syndrome (which includes different subtypes of depression) could be consistent with initial symptoms of a degenerative brain process.

The aim of this paper is to study geriatric depression syndrome by contrasting cognitive differences, vascular comorbidity, and sociological risk factors in the following patient groups:

1. Late-onset depressive patients with depressive episodes first appearing after the age of 60 years.

2. Early-onset depressive patients with depressive episodes first appearing before the age of 60 years.

3. Normal subjects (those lacking signs and symptoms of depression or cognitive impairment).

Inclusion criteria:

- Patients who present depressive symptoms that are due to psychiatric causes or are related with dementia (Clinical Dementia Rating Scale 1 [CDR]).
- Patients aged more than 55 years and less than 80 years.

- Patients with Hamilton Depression Scale $>9$ points. Exclusion criteria

- Patients with history of drug or alcohol abuse.

- Patients with neurological diseases (except dementia).

- Patients with moderate or severe dementia (CDR 2, or CDR 3).

- Patients with schizophrenia or schizoaffective disorder.

\section{Materials and methods}

We recruited 76 patients from two Buenos Aires communitybased outpatient hospitals, Hospital General Zubizarreta (public health system) and CEMIC University Hospital (private health system) that seek medical advice due to memory problems, all of whom exhibited depressive symptoms. In addition, we recruited 17 normal controls from the community.

Depressive patients were divided into two different groups: an early-onset depression group (39 patients) consisting of patients first exhibiting depressive episodes before the age of 60 years; and a late-onset depression group (37 patients), which included patients with depressive episodes starting after the age of 60 years.

All of them were assessed using a semistructured neuropsychiatric interview (administered by specialized psychiatrists and neurologists). Depressive syndromes were categorized into different diagnoses according to the Diagnostic and Statistical Manual of Mental Disorders (DSM IV) ${ }^{13}$ and International Codification of Diseases (ICD 10) criteria $^{14}$ using schedules for clinical assessment in neuropsychiatry (SCAN 2.1). ${ }^{15}$ Other psychiatric scales were utilized, including Hamilton Depression Scale ${ }^{16}$ to evaluate level of depression and Hamilton Anxiety Scale ${ }^{17}$ to determine level of anxiety.

Patients and normal controls were matched by age, education and overall cognitive status using the Mini-Mental State Examination (MMSE). ${ }^{18}$

We assessed vascular risk factors and co-morbidities such as high blood pressure (HBP), high cholesterol level (HCL), heavy smoking, cerebrovascular disease (CVD), and heart diseases. Additionally, we evaluated sociological risk factors of depression, such as marital status (married or unmarried; unmarried patients included in this research paper were individuals that live alone and have no emotional support) and level of activity (active or passive).

In order to investigate the different cognitive profiles, each patient underwent an extensive neuropsychological battery to evaluate the following areas of cognitive ability: 
- Orientation: MMSE. ${ }^{18}$

- Attention: Digit span (forward and backward); ${ }^{19}$ Trail making test " $\mathrm{A}$ ". ${ }^{20}$

- Language: Boston Naming Test (BNT); ${ }^{21}$ vocabulary; ${ }^{22}$ semantic fluency (SF);23 verbal intellectual quotient (IQ), ${ }^{22}$ verbal fluency (VF). ${ }^{23}$

- Memory: Signoret memory battery, ${ }^{24}$ episodic memory: immediate logic memory (ILM), delayed logic memory (DLM); verbal serial learning (VSL), delayed serial memory (DSM), cued recall (CR), recognition (Recog). Buschke Selective Reminding Test, free recall (BSRT fr); Buschke Selective Reminding Test, cued recall (BSRT cr). ${ }^{25}$

- Abstraction and reasoning: similarities and matrix reasoning. ${ }^{22}$

- Visuospatial abilities: block design; ${ }^{22}$ clock-drawing test. ${ }^{26}$

- Executive functions: Trail Making Test "B"; ${ }^{20} \mathrm{VF} .{ }^{23}$

- IQ: Wechsler Abbreviated Scale of Intelligence. ${ }^{22}$

Written informed consent was obtained from each subject after they had been given a full explanation of the study. The research was performed in accordance with the International Conference of Harmonization Good Clinical Practice guidelines, the latest revision of the 1964 Helsinki Declaration (as amended in Seoul 2008), and the Buenos Aires Government Health Authorities.

\section{Data analysis}

Data was analyzed using the Statistical Package for Social Sciences version $14^{27}$ statistical package.

Demographic variables for both populations (patients and controls) as well as the results of neuropsychiatric and neuropsychological general global tests were expressed as means, standard deviation and medians. Quantitative variables were compared using analysis of variance (ANOVA). Scheffe, Games-Howell, and Dunnet tests were also performed for multiple comparisons.

The relationship between qualitative variables was compared by the chi-squared test. Predictive factors for depression were analyzed using the odds ratio (OR) with $95 \%$ confidence intervals $(95 \% \mathrm{CI})$.

\section{Results}

\section{Demographic data}

The mean age of depression onset for the early-onset depressive group was 44.84 (standard deviation [SD], 12.72) and for the late-onset depressive group was 68.29 (SD, 7.98). There were no significant differences in age and education among the three groups. There were no statistically significant general cognitive differences (assessed by MMSE) between the two depressive patient groups (late- and early-onset), yet there was a significant variation in general cognitive level (assessed by MMSE) between depressive patients and normal controls $(P<0.05)$ (see Table 1$)$.

\section{Neuropsychiatric diagnoses}

Diagnostic algorithms were obtained from SCAN 2.1 15 according to DSM IV ${ }^{13}$ and ICD 10 criteria. $^{14}$

Patients with early-onset depression $(\mathrm{N}=39)$ were diagnosed as follows: major depression $(\mathrm{N}=20$, seven of whom had bipolar disorder), dysthymia $(\mathrm{N}=7)$, unspecified mood disorder $(\mathrm{N}=3)$, mood disorder due to a medical condition ( $\mathrm{N}=6$, three of whom had vascular dementia, two had Alzheimer dementia, and one had frontotemporal dementia).

Patients with late-onset depression $(\mathrm{N}=37)$ were diagnosed as follows: dysthymia $(\mathrm{N}=13)$, unspecified mood disorder $(\mathrm{N}=11)$, major depression $(\mathrm{N}=6)$, mood disorder due to a medical condition ( $\mathrm{N}=7$; three of whom had vascular dementia and four had Alzheimer dementia).

Dementia diagnosis was made according to DSM IV, ${ }^{13}$ NINCDS ADRDA (National Institute of Neurological and Communicative Diseases and Stroke/Alzheimer's Disease and Related Disorders Association) ${ }^{28}$ criteria for probable Alzheimer disease, NINDS AIREN (National Institute of Neurological Disorders and Stroke/Association Internationale pour la Recherché et l'Enseignement en Neurosciences) ${ }^{29}$ for vascular dementia and Lund and Manchester ${ }^{30}$ criteria for frontotemporal dementia were used.

\section{Neuropsychological assessment Depressive patients versus normal controls}

We found a wide variation in performance between depressive patients and normal controls in most cognitive functions:

Table I Demographic data

\begin{tabular}{|c|c|c|c|c|}
\hline & Early-onset depression & Late-onset depression & Normal controls & $P$ value \\
\hline Age (years) & $65.4 \pm 7.8$ & $69.4 \pm 7.6$ & $65.4 \pm 6.1$ & NS \\
\hline Educational level (years) & $9.8 \pm 4.3$ & $9.8 \pm 4.3$ & $12.5 \pm 3.8$ & NS \\
\hline MMSE & $26.4 \pm 3.5$ & $25.8 \pm 4.5$ & $29.0 \pm 1.0$ & $0.015^{*}$ \\
\hline
\end{tabular}

Notes: Values expressed are mean \pm standard deviation. *Significant differences: $P<0.05$. NS: nonsignificant differences $(P>0.05)$. Abbreviation: MMSE, Mini-Mental State Examination. 
memory, attention, language, and executive functions $(P<0.005)$ (see Table 2$)$. The most significant differences were found in memory $(P<0.0001)$ : ILM, DLM, VSL, DSM $(P<0.0001)$; SF $(P<0.0001)$; VF; and digit-symbol $(P<0.0001)$. As regards IQ, block design, performance IQ, and global IQ showed a significant variation $(P<0.0001)$ between controls and depressive patients (see Table 2).

\section{Late- versus early-onset depression patients}

Memory tests revealed significant differences in deferred serial memory $(P<0.05)$, as late-onset depression patients scored lower and exhibited more severe impairment than early-onset depression patients. Moreover, late-onset patients were poorer performers in all memory domains (see Table 2).

Late-onset depressive patients had the worst performance in memory domain while early-onset depressive patients had poorer functioning in executive tests (see Table 2).

\section{Neuropsychiatric scales}

Both Hamilton Depression Scale and Hamilton Anxiety Scale scores did not significantly differ between the two groups.

Table 2 Neuropsychological assessment

\begin{tabular}{|c|c|c|c|c|}
\hline Tests & $\begin{array}{l}\text { Early-onset } \\
\text { depression } \mathbf{N}=39\end{array}$ & $\begin{array}{l}\text { Late-onset } \\
\text { depression } \mathbf{N}=37\end{array}$ & $\begin{array}{l}\text { Normal controls } \\
N=17\end{array}$ & $P$ value \\
\hline \multicolumn{5}{|l|}{ Memory } \\
\hline Immediate logic memory & $5.0 \pm 2.4$ & $4.3 \pm 2.5$ & $7.9 \pm 1.8$ & $0.000 \mathrm{I} * *$ \\
\hline Delayed logic memory & $4.6 \pm 2.7$ & $3.7 \pm 2.7$ & $7.5 \pm 2.0$ & $0.000 I^{* *}$ \\
\hline Verbal serial learning & $7.4 \pm 2.4$ & $6.5 \pm 2.4$ & $9.7 \pm 1.6$ & $0.000 \mathrm{I} * *$ \\
\hline Delayed serial memory & $5.8 \pm 2.7$ & $4.0 \pm 3.1$ & $8.4 \pm 1.9$ & $0.0001 * * 8$ \\
\hline Cued recall & $8.6 \pm 3.2$ & $7.1 \pm 3.6$ & $11.2 \pm 0.9$ & $0.0001 * *$ \\
\hline Recognition & $10.3 \pm 2.3$ & $9.9 \pm 2.9$ & $1 \mathrm{I} .7 \pm 0.4$ & $0.035^{*}$ \\
\hline Buschke memory battery (free recall) & $6.5 \pm 1.9$ & $5.2 \pm 2.8$ & $7.4 \pm 1.1$ & $0.005^{*}$ \\
\hline Buschke memory battery (cued recall) & $7.0 \pm 1.4$ & $5.9 \pm 2.5$ & $7.6 \pm 1.0$ & $0.013^{*}$ \\
\hline \multicolumn{5}{|l|}{ Language } \\
\hline Boston Naming Test & $43.2 \pm 8.2$ & $43.9 \pm 9.3$ & $52.9 \pm 4.0$ & $0.001 *$ \\
\hline Semantic fluency & $12.4 \pm 4.0$ & $13.5 \pm 5.2$ & $20.1 \pm 4.7$ & $0.0001 * *$ \\
\hline Verbal fluency & $9.6 \pm 4.6$ & $\mathrm{II} .4 \pm 4.8$ & $15.4 \pm 3.4$ & $0.0001 * *$ \\
\hline Vocabulary & $44.3 \pm 12.6$ & $47.5 \pm 11.7$ & $51.3 \pm 19.6$ & NS \\
\hline \multicolumn{5}{|l|}{ Attention } \\
\hline Trail Making Test “A” & $82.3 \pm 57.6$ & $82.0 \pm 59.6$ & $50.8 \pm \mid 8.1$ & $0.00 I^{*}$ \\
\hline Digit span (forward) & $5.0 \pm 1.0$ & $5.3 \pm 1.2$ & $6.1 \pm 1.0$ & $0.002 *$ \\
\hline Digit-Symbol & $23.4 \pm 11.5$ & $25.6 \pm 15.7$ & $45.0 \pm 10.6$ & $0.000 I^{* *}$ \\
\hline Digit span (backward) & $3.5 \pm 1.0$ & $3.5 \pm 0.9$ & $4.5 \pm 1.3$ & $0.004^{*}$ \\
\hline \multicolumn{5}{|l|}{ Executive functions } \\
\hline Trail Making Test “B” & $239.3 \pm 160.4$ & $231.8 \pm 148.8$ & $115.4 \pm 43.7$ & $0.009 *$ \\
\hline Verbal fluency & $9.6 \pm 4.6$ & $1 \mathrm{I} .3 \pm 4.8$ & $15,4 \pm 3,4$ & $0.000 I^{* *}$ \\
\hline \multicolumn{5}{|l|}{ Visuospatial abilities } \\
\hline Clock-drawing test & $5.2 \pm 2.3$ & $5.2 \pm 2.3$ & $6.6 \pm 0.6$ & $0.045^{*}$ \\
\hline Block design & $41.4 \pm 7.5$ & $44.8 \pm 11.0$ & $58.2 \pm 11.6$ & $0.000 I^{* *}$ \\
\hline \multicolumn{5}{|l|}{ Abstraction and logic reasoning } \\
\hline Similarities & $42.0 \pm 11.0$ & $47.4 \pm 10.3$ & $52.0 \pm 8.2$ & $0.021^{*}$ \\
\hline Matrix reasoning & $40.0 \pm 9.5$ & $42.3 \pm 13.0$ & $55.0 \pm 6.4$ & $0.003^{*}$ \\
\hline \multicolumn{5}{|l|}{ Intellectual quotient } \\
\hline Verbal IQ & $90.5 \pm 14.4$ & $95.6 \pm 16.8$ & $107.4 \pm 11.6$ & $0.014^{*}$ \\
\hline Performance IQ & $86.4 \pm 11.3$ & $91.3 \pm 15.5$ & $110.4 \pm 8.7$ & $0.000 I^{* *}$ \\
\hline Global IQ & $87.5 \pm 23.4$ & $93.7 \pm 14.0$ & $110.5 \pm 8.3$ & $0.000 \mathrm{I} * *$ \\
\hline
\end{tabular}

Notes: Neuropsychological battery values expressed are mean + standard deviation. *Significant differences: $P<0.05$ between normal and (early- and late-onset) depression patients. ${ }^{8}$ Significant differences between early- and late-onset depression patients.

Abbreviations: IQ, intelligence quotient; NS, nonsignificant differences $(P>0.05)$. 
Both depressive groups displayed similar levels of anxiety and depression (see Table 3).

\section{Depressive patients versus normal controls}

\section{Vascular risk factors and comorbidity}

There were nonsignificant differences between depressive patients and normal control groups with respect to vascular risk factors or comorbidities (see Table 5).

\section{Sociological risk factors for depression}

Significant differences $(P<0.05)$ were immediately apparent between depressive patients and normal controls in sociological risk factors, such as level of activity. The OR for developing depression was 6.02 in inactive patients (see Table 4).

\section{Late- versus early-onset depression patients}

\section{Vascular risk factors and comorbidity}

Significant differences were observed in cholesterol levels $(P<0.05)$ between both depressive subtypes (early versus late); high cholesterol levels were especially prevalent in early-onset depressive patients (see Table 5).

\section{Sociological risk factors of depression}

Significant differences $(P<0.05)$ were shown in marital status between depressive groups, with a tendency towards lack of a stable emotional environment in early-onset patients (OR, 4.6). However, activity levels were similar in both groups (see Table 5).

As demented patients were present in both depression groups and we thought this might have some kind of implication on neuropsychological results, we excluded these patients (six early-onset depression patients with mood disorder due to a medical condition and seven late-onset depression patients with mood disorder due a to medical condition) and analyzed the new results.

Table 3 Neuropsychiatric assessment

\begin{tabular}{llll}
\hline $\begin{array}{l}\text { Neuropsychiatric } \\
\text { assesment }\end{array}$ & $\begin{array}{l}\text { Early-onset } \\
\text { depression } \\
\mathbf{N}=\mathbf{3 9}\end{array}$ & $\begin{array}{l}\text { Late-onset } \\
\text { depression } \\
\mathbf{N}=\mathbf{3 7}\end{array}$ & $\boldsymbol{P}$ value \\
\hline Hamilton Anxiety Scale & $17.5 \pm 8.0$ & $14.1 \pm 5.7$ & NS \\
Hamilton Depression Scale & $17.1 .4 \pm 7.1$ & $15.5 \pm 4.4$ & NS \\
\hline
\end{tabular}

Note: Values expressed are mean + standard deviation. Abbreviation: NS, nonsignificant differences $(P>0.05)$.

\section{Neuropsychological assessment Depressive patients (without demented patients) versus normal controls}

We found remarkable differences in performance between depressive patients and normal controls in most cognitive functions, particularly in memory, attention, language, and executive functions $(P<0.005)$ (see Table 6). However, performance in visuospatial function (clock-drawing test) did not differ significantly. In spite of the fact that we removed demented patients from both groups, we observed a similar neuropsychological pattern to the one described above.

Early-onset depression: this group of depressive patients exhibited greater impairment in executive functions (VF) and attention (digit span forward and backward) than normal controls (see Table 6).

In late-onset depression patients, the memory domain was remarkably affected in comparison to normal controls $(P<0.05)$ (see Table 6).

This contributes to support even more the fact that a different neuropsychological profile exists between late- and early-onset depression patients.

\section{Discussion}

This study revealed that depressive patients underwent a general cognitive impairment, evidenced by differences in neuropsychological test performance relative to normal controls; performance differences were especially pronounced in memory domain and executive functions. Clinical studies have shown that diseases related

Table 4 Risk factors. Depressive patients versus normal controls

\begin{tabular}{lllll}
\hline Risk factors & Depressives & Controls & P value* & OR (CI) \\
\hline $\begin{array}{l}\text { Level of activity } \\
\text { (Passive/Active) }\end{array}$ & $(43 / 23)$ & $(4 / 13)$ & 0.005 & $6.07(2-20)$ \\
$\begin{array}{l}\text { Marital status } \\
\text { (Married/Lonely) }\end{array}$ & $(25 / 42)$ & $(3 / 12)$ & NS & \\
$\begin{array}{l}\text { High blood } \\
\text { pressure level } \\
\text { (Yes, No) }\end{array}$ & $(33 / 42)$ & $(4 / 13)$ & NS & \\
$\begin{array}{l}\text { Diabetes (Yes, No) } \\
\text { High cholesterol }\end{array}$ & $(3 / 68)$ & $(0 / 17)$ & NS & \\
$\begin{array}{l}\text { level (Yes, No) } \\
\text { Heart disease } \\
\text { (Yes, No) }\end{array}$ & $(24 / 51)$ & $(4 / 13)$ & NS & \\
$\begin{array}{l}\text { Cerebrovascular } \\
\text { disease (Yes, No) }\end{array}$ & $(9 / 66)$ & $(1 / 16)$ & NS & \\
$\begin{array}{l}\text { Heavy smoking } \\
\text { (Yes, No) }\end{array}$ & $(23 / 52)$ & $(7 / 10)$ & NS & \\
\hline
\end{tabular}

Note: *Chi-squared test.

Abbreviations: $\mathrm{Cl}$, confidence interval; $\mathrm{OR}$, odds ratio. 
Table 5 Risk factors in early-onset depression versus late-onset depression

\begin{tabular}{|c|c|c|c|c|}
\hline Risk factors & Early-onset & Late-onset & $P$ value* & OR (Cl) \\
\hline Level of activity (Passive/Active) & $(22 / 13)$ & $(2 \mid / / 0)$ & NS & \\
\hline Marital status (Married/Lonely) & $(19 / 17)$ & $(25 / 6)$ & 0.01 & $4.6(1.5-14)$ \\
\hline High blood pressure level (Yes, No) & $(14 / 24)$ & $(19 / 18)$ & NS & \\
\hline Diabetes (Yes, No) & $(6 / 32)$ & $(1 / 36)$ & NS & \\
\hline High cholesterol level (Yes, No) & $(23 / 15)$ & $(13 / 24)$ & 0.028 & NS \\
\hline Heart disease (Yes, No) & $(8 / 30)$ & $(|6 / 2|)$ & NS & \\
\hline Cerebrovascular disease (Yes, No) & $(4 / 34)$ & $(5 / 32)$ & NS & \\
\hline Tobacco abuse (Yes, No) & $(12 / 26)$ & $(1 \mathrm{I} / 26)$ & NS & \\
\hline
\end{tabular}

Abbreviations: $\mathrm{Cl}$, confidence interval; $\mathrm{NS}$, nonsignificant; $\mathrm{OR}$, odds ratio.

to frontostriatal dysfunction predispose patients to depression and lead to executive function impairment in problem solving, sequencing, planning, organizing, and abstracting. ${ }^{6,31}$ Moreover, geriatric depression, even in the absence of a diagnosable neurological disease, is often accompanied by executive dysfunction. ${ }^{7}$

However, the most important trend that emerged in this study was that late-onset depression patients showed greater memory impairment than the early-onset group. In addition, early-onset patients had executive dysfunction. Moreover, late-onset depression patients showed greater impairment than early-onset depression patients. This demonstrates a different neuropsychological profile between these two groups of depressive patients.

Late-onset depression patients had greater impairment in episodic memory tests while early-onset depression patients had predominance of executive dysfunction. Episodic memory is subserved by the hippocampus while executive functions are related to frontostriatal and subcortical pathways. The first symptom observed in Alzheimer disease is impairment in episodic memory which is related to hippocampal atrophy, while in vascular cognitive impairment is evidenced through executive dysfunction.

What seems to differentiate this investigation from others is that in many studies late-onset depression is related to executive dysfunction probably due to cerebrovascular disease. However, in this research executive functioning is more related to early-onset depression than to late-onset depression.

Moreover, in this investigation we included different subtypes of depressive syndromes and found that the early-onset depression group was especially prone to major depression, while the late-onset group tended to exhibit unspecified mood disorder and dysthymia.

According to the previous findings, we could speculate that late-onset depression seems to be more related to a degenerative process, as episodic memory is the predominant affected. If this is so, some subtypes of late-onset depression, that maybe do not conform DSM IV criteria for major depression such as dysthymia or unspecified mood disorder, could be a clinical prodromal of Alzheimer disease. It is currently not clear whether prior depression is a true etiologic risk factor for dementia or rather represents a prodromal clinical manifestation of dementia neuropathology. ${ }^{32}$

The loss of hippocampal volume and memory function observed in some elders with late-life depression suggests the possibility that depression may be a predispositional risk factor for Alzheimer disease in particular. Indeed, lower hippocampal volumes independently predict subsequent Alzheimer disease in groups of mild cognitively impaired patients and cognitively normal elderly patients. ${ }^{33}$ Likewise, deficits in verbal learning and memory, similar to those described in euthymic patients with history of major depression, also predict Alzheimer disease. ${ }^{34}$

Some structural magnetic resonance imaging (MRI) studies find that hippocampal atrophy is more strongly associated with late-onset than early-onset depression, suggesting that early Alzheimer disease-related pathophysiology could generate both hippocampal atrophy and depressive symptoms in some elderly persons. ${ }^{35,36} \mathrm{In}$ addition, one of these studies failed to find a significant correlation between hippocampal volume and cortisol level among elders with depression. Furthermore, the late-life depression subjects showed persistent memory and cognitive impairment at six-month follow-up despite effective treatment of mood symptoms and normalization of cortisol levels..$^{36}$ All of these data are consistent with the idea that Alzheimer disease pathology is a major cause of hippocampal atrophy in some (but not all) individuals with late-life depression, and their depressive symptoms may represent prodromal Alzheimer disease. ${ }^{32}$

Butters and colleagues propose that depression alters an individual's risk of cognitive dysfunction, shortening 
Table 6 Neuropsychological assessment

\begin{tabular}{|c|c|c|c|c|}
\hline Tests & $\begin{array}{l}\text { Early-onset } \\
\text { depression } N=32\end{array}$ & $\begin{array}{l}\text { Late-onset } \\
\text { depression } \mathbf{N}=\mathbf{3 0}\end{array}$ & $\begin{array}{l}\text { Normal controls } \\
N=17\end{array}$ & $P$ value \\
\hline \multicolumn{5}{|l|}{ Memory } \\
\hline Immediate logic memory & $5.5 \pm 2.3$ & $4.9 \pm 2.2$ & $7.9 \pm 1.8$ & $0.000 I^{*}$ \\
\hline Delayed logic memory & $5.1 \pm 2.6$ & $4.3 \pm 2.5$ & $7.5 \pm 2.0$ & $0.0001 *$ \\
\hline Verbal serial learning & $7.5 \pm 2.3$ & $7.0 \pm 2.2$ & $9.7 \pm 1.6$ & $0.000 I^{*}$ \\
\hline Delayed serial memory & $6.0 \pm 2.5$ & $4.6 \pm 3.0$ & $8.4 \pm 1.9$ & $0.000 I^{*}$ \\
\hline Cued recall & $8.8 \pm 3.2$ & $7.7 \pm 3.3$ & $11.2 \pm 0.9$ & $0.000 I^{*}$ \\
\hline Recognition & $10.3 \pm 2.4$ & $10.6 \pm 1.8$ & $1 \mathrm{I} .7 \pm 0.4$ & $0.03 *$ \\
\hline Buschke Memory battery (Immediate memory) & $6.8 \pm 1.8$ & $5.9 \pm 2.4$ & $7.4 \pm 1.1$ & $0.036^{\$}$ \\
\hline Buschke Memory battery (Cued memory) & $7.3 \pm 1.1$ & $6.5 \pm 1.9$ & $7.6 \pm 1.0$ & NS \\
\hline \multicolumn{5}{|l|}{ Language } \\
\hline Boston Naming Test & $44.5 \pm 7.7$ & $45.7 \pm 7.5$ & $52.9 \pm 4.0$ & $0.001 *$ \\
\hline Semantic Fluency & $13.1 \pm 4.0$ & $14.6 \pm 4.9$ & $20.1 \pm 4.7$ & $0.000 I^{*}$ \\
\hline Verbal Fluency & $10.4 \pm 4.4$ & $12.5 \pm 4.5$ & $15.4 \pm 3.4$ & $0.00 I^{\#}$ \\
\hline Vocabulary & $46.7 \pm 11.9$ & $49.5 \pm 10.8$ & $51.3 \pm 19.6$ & NS \\
\hline \multicolumn{5}{|l|}{ Attention } \\
\hline Trail Making Test “A” & $64.4 \pm 29.3$ & $74.3 \pm 50.6$ & $50.8 \pm \mid 8.1$ & NS \\
\hline Digit Span (forward) & $5.1 \pm 1.0$ & $5.3 \pm 1.3$ & $6.1 \pm 1.0$ & $0.010^{\#}$ \\
\hline Digit Span (backward) & $3.5 \pm 1.0$ & $3.7 \pm 0.8$ & $4.5 \pm 1.3$ & $0.032^{\#}$ \\
\hline Digit-Symbol & $27.0 \pm 9.9$ & $28.6 \pm 15.3$ & $45.0 \pm 10.6$ & $0.000 I^{*}$ \\
\hline \multicolumn{5}{|l|}{ Executive functions } \\
\hline Trail Making Test "B" & $209.2 \pm 144.5$ & $220.7 \pm 142$ & $115.4 \pm 43.7$ & $0.023^{*}$ \\
\hline Verbal fluency & $10.4 \pm 4.4$ & $12.57 \pm 4.6$ & $15,4 \pm 3,4$ & $0.00 I^{\#}$ \\
\hline \multicolumn{5}{|l|}{ Visuospatial abilities } \\
\hline Clock-drawing test & $5.56 \pm 2.1$ & $5.7 \pm 1.7$ & $6.6 \pm 0.6$ & NS \\
\hline Block design & $42.7 \pm 7.5$ & $46.3 \pm 11.3$ & $58.2 \pm 11.6$ & $0.000 I^{*}$ \\
\hline \multicolumn{5}{|l|}{ Abstraction and logic reasoning } \\
\hline Similarities & $44.0 \pm 10.9$ & $48.1 \pm 10.6$ & $52.0 \pm 8.2$ & NS \\
\hline Matrix reasoning & $40.5 \pm 9.8$ & $43.2 \pm 14.1$ & $55.0 \pm 6.4$ & $0.005^{*}$ \\
\hline \multicolumn{5}{|l|}{ Intellectual quotient } \\
\hline Verbal IQ & $93.6 \pm 13.6$ & $98.4 \pm 15.2$ & $107.4 \pm 11.6$ & $0.03^{\#}$ \\
\hline Performance IQ & $87.8 \pm 11.5$ & $93.4 \pm 16.2$ & $110.4 \pm 8.7$ & $0.0001 *$ \\
\hline Global IQ & $89.9 \pm 11.8$ & $96.1 \pm 13.9$ & $110.5 \pm 8.3$ & $0.000 I^{*}$ \\
\hline
\end{tabular}

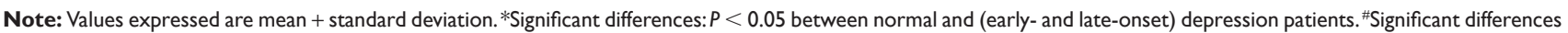

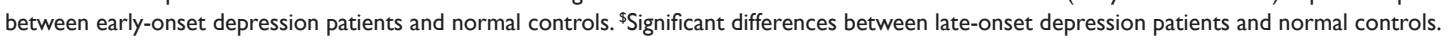

Abbreviations: NS, nonsignificant differences $(P>0.05)$; IQ, intelligence quotient.

the latent period between the development of Alzheimer disease neuropathology and the onset of clinical dementia, thus increasing the incidence and prevalence of Alzheimer disease among older adults with depression.

Many individuals with late-onset depression may be in the prodromal stage of Alzheimer disease, their hippocampus having already sustained substantial neuronal injury due to cumulative Alzheimer disease neuropathology. ${ }^{32}$

Late-onset depression and cognitive impairment usually go hand-in-hand, a trend that suggests a close association between the two. ${ }^{37,38}$ It is not known, however, which is causal. ${ }^{38,40}$ 
Clinical practice and research evidence suggest that depression is a risk factor for cognitive decline in old age. It is quite difficult to affirm this association, because these studies are limited by the assumption that cognitive impairment is a result of depression itself, and fail to explore other causal relationships. ${ }^{41-43}$ This association could not be confirmed by other investigations. ${ }^{44-47}$

Depression may very well be an early sign of, rather than an independent risk factor for, cognitive impairment, and as such, the temporal relationship between the two in old age remains unclear. In fact, the few studies that have undertaken both causal relationships have quite convincingly shown that depression in old age is a concomitant phenomenon of an already existing cognitive impairment rather than an independent risk factor.

Another important data observed in this study was that both groups scored similarly in Hamilton Depression Scale and Hamilton Anxiety Scale, which shows a degree of homogeneity in relation to the depressive symptoms.

No variable occurrences were observed in vascular risk factors and comorbidity between depressives and normal controls. However, differences were evident between depressive groups as early-onset depressives exhibited high cholesterol levels.

As regards to sociological variables, inactive patients were much more likely to develop depression than those who were engaged in regular activity (OR, 6.02). Marital status played an important role when looking at depression groups. Late-onset depression patients were more frequently married while early-onset depressives were more often unmarried (which in our investigation was related to a lack of emotional support).

Prospective studies reveal a higher incidence of depression in women than in men. ${ }^{48}$ Other potential risk factors include marital status, ${ }^{49-51}$ concomitant diseases, ${ }^{49}$ low education, functional disability (which can correlate with inactivity), ${ }^{52}$ and alcohol abuse. Social isolation, physical inactivity, and lack of leisure cognitive activity may result in lowered reserve and therefore confer additional risk for exhibiting clinical symptoms of dementia. ${ }^{32}$

\section{Conclusion}

According to the results of the present study, depressive patients (both early- and late-onset) had significantly lower performances, in comparison to normal controls, in all neuropsychological tests. Furthermore, the late-onset depression group had more cognitive impairment than the early-onset depression group, in spite of the fact that in both groups' patients with dementia were present in similar number. These results might support the theory that cognitive decline causes late-onset depression, which may be correlated with a degenerative biological brain change.

Unspecified mood disorder was significantly prevalent in the late-onset depressive group. According to DSM IV ${ }^{13}$ and ICD $10^{14}$ classifications, this diagnosis is made when mood disorders do not meet any criteria for depressive disorders, so it should be considered when evaluating late-onset depression.

Inactivity and lack of social interaction are examples of severe life stress events that may lead to increased depression in individuals.

Artero and Ritchie $^{53}$ examined the evidence for a separate nosological entity of late-onset depressive episodes. Their studies showed that late-onset depression is likely due to various underlying causes and should not be classified as an independent disease entity. van den Berg and colleagues ${ }^{54}$ divided late-onset depression patients into two subgroups with distinct etiological pathways: one through the experience of severe life stress, and the other through degenerative biological brain changes.

The literature on depression and dementia has always been somewhat contradictory. There are three main hypotheses ${ }^{55}$ that attempt to explain the association: (1) depression may be a psychological reaction to eroding cognitive capacities early in the course of dementia; (2) a common underlying central nervous system disorder may be the cause of depression, as well as cognitive decline in elderly persons; it has been shown that elderly depressed people have more frequent and more severe white matter and other subcortical abnormalities on brain magnetic resonance imaging; (3) depression may be associated with high levels of cortisol, which can lead to neuronal death and deregulation of the hypothalamicpituitary adrenal axis resulting in hippocampal atrophy and cognitive decline. Several studies have found links between late-onset depression and Alzheimer's disease. ${ }^{56-59}$

Depression is a mental disease that affects not only the psychological well-being of a patient (by causing mood disorders), but also his/her neuropsychological profile (through cognitive impairment). Geriatric depression may be a sign of brain degeneration and the initial symptom of a dementing disorder. It is important to consider this in patients whose depressive symptoms begin after the age of 60 years.

\section{Disclosures}

The authors report no conflicts of interest in this work. $\mathrm{CD}$ and RFA conceived the project, designed the study, 
supervised data collection, performed statistical analysis on collected data and wrote the paper. CD, CS, MI, FG, FT, and PS were involved in data collection and writing assistance. All authors have read and approved the final manuscript. This research was supported by scientific research grants from the CONICET and CIS-GCBA of Argentina (CD, CMS, and RFA) and from the Ministry of Health of Argentina (Carrillo-Oñativia Grant 2005-2006-CD, CMS, and RFA). The views expressed in the publication are those of the authors and not necessarily those of the Ministry of Health of Argentina or the Secretary of Health of Buenos Aires Government.

\section{References}

1. Krishnan KRR. Neuroanatomic substrates of depression in the elderly. J Geriatr Psychiatry Neurol. 1993;1:39-58.

2. Krishnan KRR, Hays JC, Blazer DG. MRI-defined vascular depression. Am J Psychiatry. 1997;154:497-500.

3. Coffey CE, Figiel GS, Djang WT, et al. Subcortical hyperintensity in MRI: a comparison of normal and depressed elderly subjects. Am J Psychiatry. 1990;147:187-189.

4. Alexopoulos GS. Clinical and biological findings in late-onset depression. In: Tasman A, Goldfinger SM, Kaufman CA, editors. Review of Psychiatry. Washington, DC: American Psychiatric Press; 1990. p. 9.

5. Alexopoulos GS. Geriatric depression in primary care. Int $J$ Geriatr Psychiatry. 1996;11:397-400.

6. Lesser IM, Boone KB, Mehringer CM, et al. Cognition and white matter hyperintensities in older depressed patients. Am J Psychiatry. 1996;153:1280-1287.

7. King D, Caine ED. Cognitive impairment and major depression: beyond the pseudodementia syndrome. In: Grant I, Adams KM, editors. Neuropsychological Assessment of Neuropsychiatric Disorders. 2nd ed. New York, NY: Oxford University Press Inc; 1996. p. 200-217.

8. Alexopoulos GS, Meyers BS, Young RC, et al. Recovery in geriatric depression. Arch Gen Psychiatry. 1996;53:305-312.

9. Alexopoulos GS. Role of executive function in late-life depression. J Clin Psychiatry. 2003;64(Suppl 14):18-23.

10. Bench CJ, Friston KJ, Brown RG, et al. The anatomy of melancholia: focal abnormalities of cerebral blood flow in major depression. Psychol Med. 1992;22:607-615.

11. Lesser IM, Mena I, Boone KB, et al. Reduction of cerebral blood flow in older depressed patients. Arch Gen Psychiatry. 1994;51:677-686.

12. Rapp MA, Dahlman K, Sano M, Grossman HT, et al. Neuropsychological differences between late-onset and recurrent geriatric major depression. Am J Psychiatry. 2005;162:691-698.

13. American Psychiatric Association. Diagnostic and Statistical Manual of Mental Disorders. 4th ed. Text Revision. Washington, DC: APA; 2000.

14. World Health Organization. International Codification of Diseases, 10th ed (ICD 10). Geneva, Switzerland: World Health Organization; 1990.

15. Wing JK, Babor T, Brugha T, et al. SCAN. Schedules for Clinical Assessment in Neuropsychiatry. Arch Gen Psychiatry. 1990;47(6); 589-593.

16. Hamilton M. A rating scale for depression. J Neurol Neurosurg Psychiatry. 1960;23:56-62.

17. Hamilton M. The assessment of anxiety states by rating. $\mathrm{Br} J \mathrm{Med}$ Psychol. 1959;32:50-55.

18. Folstein MF, Folstein SE, McHugh PR. 'Mini-Mental State': a practical method for grading the cognitive state of patients for the clinician. J Psychiatr Res. 1975;12:196-198.
19. Wechsler D. Test de inteligencia para adultos (WAIS). Buenos Aires, Argentina: Editorial Paidos; 1988.

20. Reitan RM. Validity of the Trail Making Test as an indication of organic brain damage. Percept Mot Skills. 1958;8:271.

21. Allegri RF, Mangone CA, Rymberg S, et al. Spanish version of the Boston Naming Test in Buenos Aires. Clin Neuropsychol. 1997;11(4):416-420.

22. Wechsler D. Abbreviated Scale of Intelligence (WASI). San Antonio, TX: The Psychological Corporation; 1999.

23. Benton AL, Hannay HJ, Varney NR, Spreen O. Contributions to Neuropsychological Assessment. New York, NY: Oxford University Press; 1983.

24. Signoret JL, Batterie d'efficience mnesique. Paris, France: Editions Scientifiques Elsevier; 1991.

25. Buschke H. Selective reminding for analysis of memory and learning. Journal of Verbal Learning and Verbal Behavior. 1973;12:543-550.

26. Freedman M, Learch K, Kaplan E, Winocur G, Shulman KI, Delis D. Clock Drawing: SA Neuropsychological Analysis. New York, NY; Oxford University Press; 1994.

27. Statistical Package for the Social Sciences. SPSS for Windows. [14.0] 2006. Chicago, IL: SPSS Inc.; 2006.

28. McKhann G, Drachman D, Folstein M, et al. Clinical diagnosis of Alzheimer's disease: Report of the NINCDS ADRDA work group under the auspices of Department of Health and Human Services Task Force on Alzheimer's disease. Neurology. 1984;34(7):939-944.

29. Román GC, Tatemichi TK, Erkinjuntti T, et al. Vascular dementia: diagnostic criteria for research studies. Report of the NINDS-AIREN International Workshop. Neurology. 1993;43:250-260.

30. Neary D, Snowden JS, Gustafson L, et al. Frontotemporal lobar degeneration: a consensus on clinical diagnostic criteria. Neurology. 1998;51(6):1546-1554.

31. Alexopoulos GS. The depression-executive dysfunction syndrome of late life: a specific target for D3 receptor antagonists? Am J Geriatr Psychiatry. 2001;9:1-8.

32. Butters MA, Young JB, Lopez O, et al. Pathways linking late-life depression to persistent cognitive impairment and dementia. Dialogues Clin Neurosci. 2008;10:345-357.

33. Jack CR Jr, Petersen RC, Xu YC, et al. Prediction of AD with MRI-based hippocampal volume in mild cognitive impairment. Neurology. 1999;52:1397-1403.

34. Sheline YI, Sanghavi M, Mintun MA, Gado MH. Depression duration but not age predicts hippocampal volume loss in medically healthy women with recurrent major depression. $J$ Neurosci. 1999; 19:5034-5043.

35. Steffens DC, Byrum CE, McQuoid DR, et al. Hippocampal volume in geriatric depression. Biol Psychiatry. 2000;48:301-309.

36. Lloyd AJ, Ferrier IN, Barber R, Gholkar A, Young AH, O'Brien JT. Hippocampal volume change in depression: late- and early-onset illness compared. Br J Psychiatry. 2004;184:488-495.

37. Migliorelli R, Teson A, Sabe L, et al. Prevalence and correlates of dysthymia and major depression among patients with Alzheimer's disease. Am J Psychiatry. 1995;152:37-44.

38. Jorm AF, van Duijn CM, Chandra V, et al; EURODEM Risk Factors Research Group. Psychiatric history and related exposures as risk factors for Alzheimer's disease: a collaborative re-analysis of case-control studies. Int J Epidemiol. 1991;20:S43-S47.

39. Zubenko GS, Zubenko WN, McPherson S, et al. A collaborative study of the emergence and clinical features of the major depressive syndrome of Alzheimer's disease. Am J Psychiatry. 2003;160:857-866.

40. Schweitzer I, Tuckwell V, O'Brien J, et al. Is late onset depression a prodrome to dementia? Int J Geriatr Psychiatry. 2002;17:997-1005.

41. Devanand DP, Sano M, Tang MX, et al. Depressed mood and the incidence of Alzheimer's disease in the elderly living in the community. Arch Gen Psychiatry. 1996;53:175-182.

42. Paterniti S, Verider-Taillerfer MH, Dufouil C, et al. Depressive symptoms and cognitive decline in elderly people. Br J Psychiatry. 2002;181:406-410. 
43. Yaffe K, Blackwell T, Gore R, et al. Depressive symptoms and cognitive decline in nondemented elderly women. Arch Gen Psychiatry. 1999;56:425-430.

44. Dufouil C, Fuhrer R, Dartigues JF, et al. Longitudinal analysis of the association between depressive symptomatology and cognitive deterioration. Am J Epidemiol. 1996;144:634-631.

45. Henderson AS, Korten AE, Jacomb PA, et al. The course of depression in the elderly: a longitudinal community-based study in Australia. Psychol Med. 1997;27:119-129.

46. Cervilla JA, Prince M, Joels S, et al. Does depression predict cognitive outcome 9 to 12 years later? Evidence from a prospective study of elderly hypertensives. Psychol Med. 2000;30:1017-1023.

47. Broday H, Luscombe G, Anstey KJ, et al. Neuropsychological performance and dementia in depressed patients after 25-year follow-up: a controlled study. Psychol Med. 2003;33:1263-1275.

48. Gallo JJ, Royall DR, Anthony DC. Risk factors for the onset of major depression in middle age and late life. Soc Psychiatry Psychiatr Epidemiol. 1993;28(3):101-108.

49. Harlow SD. A longitudinal study of risk factors for depressive symptomatology in elderly widowed and married women. Am J Epidemiol. 1991;134:526-538.

50. Mendes de Leon CF, Kasl SV, Jacobs S. A prospective study of widowhood and changes in symptoms of depression in a community sample of the elderly. Psychol Med. 1994;24(3):613-624.

51. Zisook S, Shuchter SR. Depression through the first year after the death of a spouse. Am J Psychiatry. 1991;148:1346-1352.

52. Bruce ML, Kim K, Leaf PJ, Jacobs S. Depressive episodes and dysphoria resulting from conjugal bereavement in a prospective community sample. Am J Psychiatry. 1990;147(5):608-611.
53. Artero S, Ritchie K. Late onset depressive episodes in the elderly: examination of evidence for a separate nosological entity. Psychogeriatrics. 2001;1:194-202.

54. Van den Berg MD, Oldehinkel AJ, Bouhuys A, et al. Depression in later life: three etiologically different subgroups. $J$ Affect Disord. 2001;65:19-26.

55. Comijs H, Jonker C, Beekman ATF, et al. The association between depressive symptoms and cognitive decline in community-dwelling elderly persons. Int J Geriatr Psychiatry. 2001;16:361-367.

56. Jorm AF. History of depression as a risk factor for dementia: an updated review. Aust NZ J Psychiatry. 2001;35:776-781.

57. Kokmen E, Beard CM, Chandra V, et al. Clinical risk factors for Alzheimer's disease: a population-based case-control study. Neurology. 1991;41:1393-1397.

58. Speck CE, Kukull WA, Brenner DE, et al. History of depression as a risk factor for Alzheimer's disease. Epidemiology. 1995;6:366-369.

59. van Duijn CM, Clayton DG, Chandra V, et al; EURODEM Risk Factors Research Group. Interaction between genetic and environmental risk factors for Alzheimer's disease: a reanalysis of case-control studies. Genet Epidemiol. 1994;11:539-551.

60. Hoptman MJ, Gunning-Dixon FM, Murphy CF, et al. Blood pressure and white matter integrity in geriatric depression. J Affect Disord. 2009; 115:171-176.

61. Flicker L. Vascular factors in geriatric psychiatry: time to take a serious look. Curr Opin Psychiatry. 2008;21:551-554.
Neuropsychiatric Disease and Treatment

\section{Publish your work in this journal}

Neuropsychiatric Disease and Treatment is an international, peerreviewed journal of clinical therapeutics and pharmacology focusing on concise rapid reporting of clinical or pre-clinical studies on a range of neuropsychiatric and neurological disorders. This journal is indexed on PubMed Central, the 'PsycINFO' database and CAS, and is the official

\section{Dovepress}

journal of The International Neuropsychiatric Association (INA). The manuscript management system is completely online and includes a very quick and fair peer-review system, which is all easy to use. Visit http://www.dovepress.com/testimonials.php to read real quotes from published authors. 